\title{
Dengue una enfermedad emergente y re-emergente en América
}

\author{
Venegas $\mathbf{J}^{1}$., Dácil Rivera O., ${ }^{1}$ Vergara $C^{2}$., Lisette Lapierre A., ${ }^{1}$ \\ ${ }^{1}$ Departamento de Medicina Preventiva Animal, Facultad de Ciencias Veterinarias y Pecuarias, Universidad \\ de Chile \\ ${ }^{2}$ Agencia Chilena para la Inocuidad Alimentaria ACHIPIA \\ Universidad de Chile, Facultad de Ciencias Veterinarias y Pecuarias. Santa Rosa 11.735, La Pintana. \\ Casilla 2, correo 15, La Granja. Email: llapierre@uchile.cl
}

\begin{abstract}
Resumen
El Dengue es una enfermedad infecciosa, producida por un arbovirus cuyo único reservorio es el hombre. El virus utiliza como vector biológico al mosquito Aedes aegypti o al mosquito Aedes albopictus. La sintomatología se presenta habitualmente como un cuadro febril denominado dengue clásico, que se caracteriza por fiebre alta de presentación aguda, de duración limitada (2 a 7 días), con intenso malestar general, acompañado de erupción cutánea. Puede presentar síntomas hemorrágicos de escasa intensidad, como petequias y sangramiento gingival. El tratamiento es sintomático y el paciente mejora completamente en aproximadamente 7 días. Esta forma de dengue no produce mortalidad. Sin embargo, existen otras presentaciones de la enfermedad que pueden llegar a manifestaciones graves del tipo hemorrágicas con muerte, lo que se presenta en el 5\% de los enfermos. El dengue es un problema creciente de salud pública, que afecta a más de 100 países en el mundo, con más de 50 millones de casos informados cada año. Los cuatro tipos de dengue, están circulando en América, donde los casos aumentaron en los últimos años en forma explosiva. Si bien, en Chile continental no se ha documentado la existencia del mosquito vector del dengue de forma endémica, si se ha hecho en Chile Insular, más específicamente en Isla de Pascua, donde desde el año 1999, se incorporó a la lista de enfermedades de declaración obligatoria (D.S. $\mathrm{N}^{\circ}$ 158) estableciendo su vigilancia. Los factores que han llevado a la emergencia de esta enfermedad son principalmente el cambio climático, que ha modificado el nicho ecológico de los mosquitos de la familia Aedes. También la urbanización, la falta de control del vector, las fallas en infraestructura básica y el pobre saneamiento ambiental. La intervención primaria de salud pública ha ido por la línea del uso de insecticidas para el control del vector y la detección temprana de casos. No existe aún una vacuna efectiva, sin embargo, actualmente se están realizando esfuerzos en esta materia.
\end{abstract}

Palabras clave: Enfermedad de dengue, virus del dengue, emergente y re-emergente.

\section{Introducción}

El dengue es un problema creciente para la Salud Pública mundial debido a varios factores entre los que podemos mencionar el cambio climático, el aumento de la población mundial en áreas urbanas de manera rápida y desorganizada, la insuficiente provisión de agua potable que obliga al almacenamiento en recipientes caseros habitualmente descubiertos, la inadecuada recolección de residuos y la gran producción de recipientes descartables y neumáticos desechados que sirven como criaderos de mosquitos. A estos factores se suman, el aumento de los viajes y las migraciones, y el control insuficiente de los vectores, todos elementos que impactan en la proliferación de esta enfermedad (MINSAL, 2012a). En el año 2005, el dengue fue la enfermedad vírica atribuida a un mosquito que más afectó a los seres humanos; su 
distribución global es comparable con la distribución de la malaria. Se calcula que 2,5 mil millones de personas viven en áreas expuestas al riesgo de transmisión epidémica. Todos los años se registran decenas de millones de casos de dengue $\mathrm{y}$, cientos de miles de ellos son casos de dengue hemorrágico. La mayoría de los casos mortales se dan en niños y adultos jóvenes (MINSAL, 2012a).En América la situación de la enfermedad se ha agravado durante los últimos 20 años con el incremento considerable del número de casos y de países afectados, y una mayor frecuencia de las manifestaciones graves del dengue hemorrágico. Se estima que en la actualidad, entre 2.500 a 3.000 millones de personas viven en áreas de riesgo de transmisión del dengue; anualmente ocurren alrededor de 50 millones de infecciones, con 500.000 casos de dengue hemorrágico y 21.000 muertes (OPS, 2012).

Chile erradicó el vector del dengue en el año 1961, lo que fue certificado oficialmente por la Organización Panamericana de la Salud. Esta situación cambió con la aparición del vector en Chile Insular el año 2000 (MINSAL, 2012b).

En el 2003, el Ministerio de Salud amplió la vigilancia vectorial desde la Región de

Arica y Parinacota hasta la Región Metropolitana, a objeto de vigilar la introducción de estos vectores desde los países vecinos. A la fecha, no se ha pesquisado Aedes aegypti en el territorio continental (MINSAL, 2012a). Chile, ha adoptado la Estrategia de Gestión Integrada de Dengue (EGI-Dengue) promovido por la OMS, con el fin de maximizar las acciones de prevención y control (MINSAL, 2012a). Esta estrategia contiene un enfoque multidisciplinario integrado de los componentes de entomología, epidemiología, laboratorio, atención al paciente y promoción de la salud (MINSAL, 2012b).

\section{Descripción del virus}

El virus causante del dengue es un arbovirus del género flavivirus, perteneciente a la familia flaviviridae. Es un virus esférico, con un diámetro de 40- 60 nm, su genoma ARN es de simple cadena, de polaridad negativa, el cual está protegido por una cápside proteica que a su vez está rodeada por una estructura lipoproteica. Debido a esta estructura lipídica, los flavivirus son sensibles al cloroformo, la acetona, a los pH ácidos y temperaturas elevadas, a luz ultravioleta, radiaciones gamma y diversos desinfectantes como son alcohol, fenol, yodo, cloro, entre otros (Guzmán y Kourí, 2001).

El virus posee cuatro serotipos, los que se han denominado de forma genérica DEN-1, DEN-2, DEN3 y DEN-4. Cada serotipo produce inmunidad específica de por vida contra el mismo serotipo, así como una inmunidad cruzada a corto plazo contra los otros tres serotipos, que puede durar varios meses, sin embargo la inmunidad inducida por un serotipo es poco protectora contra otro serotipo.

\section{Ciclo de transmisión del dengue}

El ciclo de transmisión del virus del dengue se realiza mediante el mosquito Aedes aegypti (Figura 1). Una persona infectada posee el virus circulando en su sangre, por aproximadamente cinco días. Durante este tiempo, un mosquito hembra pica a la persona y se infecta al ingerir sangre que contiene el virus. Inmediatamente, el virus se replica dentro del mosquito, de ocho a doce días (Marcano-Pasquier, 2010). Luego, el mosquito durante toda su vida puede transmitir el virus a las personas susceptibles. El virus se replica en la segunda persona y produce síntomas, los cuales comienzan a aparecer, en promedio de cuatro a siete días después de la picadura de mosquito, con un rango de tres a 14 días. La viremia comienza algo antes de la aparición de los síntomas y estos pueden durar de tres a 10 días, con un promedio de cinco días y pueden persistir durante varios días después de haber concluido la viremia.

Figura 1. Fotografía del mosquito Aedes aegypti

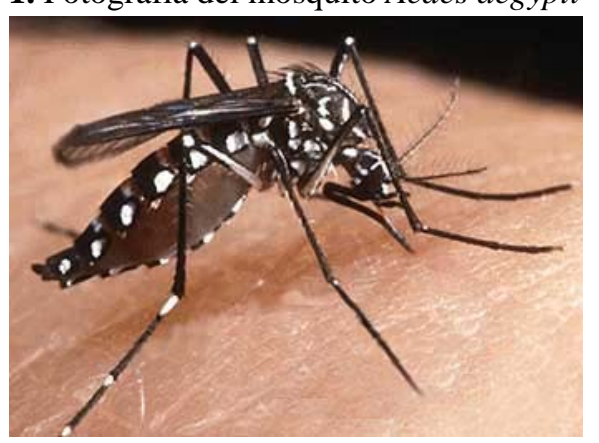




\section{Biología del Aedes Aegypti}

Los cambios climáticos observados de los últimos años, han impactado en la modificación de los nichos ecológicos en que se desarrollan muchas de las enfermedades infecciosas. Las enfermedades transmitidas por vectores y las zoonosis no son una excepción, aumentando su re-emergencia y diseminación (Mackey y Liang, 2012). En el caso del vector del dengue, este mosquito fue introducido en América, siendo una especie diseminada por el hombre por medio del transporte en barcos, aviones y transportes terrestres. Sus hábitos son netamente antropófilos y domésticos, con radicación de criaderos en la vivienda o su peridomicilio. Los depósitos de agua ubicados en objetos o construcciones, como neumáticos, baterías viejas, recipientes de todo tipo, le sirven a A. aegypti para establecer sus criaderos en agua limpia, con bajo tenor orgánico y de sales disueltas, mediante la puesta de huevos en la interfase agua-aire. Si se dan las óptimas condiciones de humedad y temperatura, el embrión evoluciona en un lapso de 2-3 días. Las larvas que emergen inician un ciclo de cuatro estados larvarios, creciendo a lo largo de tres mudas desde un largo de $1 \mathrm{~mm}$ a los 6 o $7 \mathrm{~mm}$ finales. Estas larvas se alimentan con el zoo y fitoplancton de los recipientes que habitan. Su desarrollo se completa en condiciones favorables de nutrición y con temperaturas de 25 a $29^{\circ} \mathrm{C}$, en 5 a 7 días. Son incapaces de resistir temperaturas inferiores a $10^{\circ} \mathrm{C}$ o superiores a $44^{\circ} \mathrm{C}$. El estadio pupal no requiere alimentación y entre $28^{\circ}$ y $32^{\circ} \mathrm{C}$, completa su desarrollo hasta la emergencia del adulto en 1 a 3 días. El ciclo completo de A.aegypti, de huevo a adulto, se completa en óptimas condiciones de temperatura y alimentación, en 10 días. El adulto emergente es un mosquito de color negro, con diseños blanco-plateados formados por escamas claras que se disponen simulando la forma de una "lira", en el dorso del tórax, y mostrando un anillado característico a nivel de tarsos, tibia y fémures de las patas. Las hembras son hematófagas, debido a que utilizan las proteínas de la sangre extraída para favorecer el crecimiento de sus huevos, siendo el vehículo de propagación del virus, teniendo hábitos de alimentación diurnos, en cercanía a los domicilios humanos con gran afinidad a la alimentación sobre el hombre. Los machos en tanto, se alimentan de néctar (Salvatella, 1996).

\section{Signos y sintomatología del dengue}

Las manifestaciones clínicas del dengue van desde un cuadro febril indiferenciado observado principalmente en niños pequeños, el cuadro de "Fiebre del Dengue" (FD) y la forma severa, el DH. La FD se caracteriza por fiebre elevada, astenia, anorexias, artralgias y mialgias, dolor reticular, erupción y cefalea intensa. Pueden manifestarse algunos episodios hemorrágicos menores como epistaxis y petequias y el paciente se recupera completamente en 1 semana. El DH en tanto, comienza de forma similar a FD, pero al tercer o cuarto día del comienzo de la fiebre, se produce una caída de la misma, acompañada de algún tipo de sangramiento, como petequias, epistaxis, hematemesis, melena, etc. El síndrome de shock producido por la hipovolemia generada por $\mathrm{DH}$, se observa en un menor número de casos y se caracteriza por hipotensión, piel fría e irritabilidad. El DH se ha clasificado en 4 grados según severidad (Guzmán y Kourí, 2001):

-Grado 1: Fiebre, síntomas no específicos, prueba del torniquete positiva.

-Grado 2: Sangramiento espontáneo

-Grado 3: Fallo circulatorio

-Grado 4: Shock profundo con tensión arterial y pulso no detectables.

\section{Diagnóstico}

Es criterio diagnóstico la presencia de hemoconcentración, que se evidencia por incremento del hematocrito en $20 \%$, ascitis o efusión pleural y trombocitopenia de menos de 100.000 plaquetas/ milímetro cúbico. Sin embargo, el diagnóstico específico es por aislamiento del virus a partir del suero o homogenados de muestras de tejidos en casos fatales (hígado, bazo, ganglios) en cultivos celulares de células de mamífero, mosquitos o mediante la inoculación intratorácica en mosquitos de los géneros Toxorhynchites y Aedes. La identificación del serotipo se realiza utilizando anticuerpos monoclonales específicos a los cuatro serotipos virales. También 
puede utilizarse PCR y ELISA. (Guzmán y Kourí, 2001).

\section{Situación Mundial de la Enfermedad}

La incidencia del dengue ha aumentado en todo el mundo en los últimos decenios. La OMS calcula que cada año puede haber 50 millones de casos de dengue en todo el mundo. Sólo en 2007 se notificaron más de 890.000 casos en América, de los cuales 26.000 fueron DH (OMS, 2009).

La enfermedad es endémica en más de 100 países tanto de África, las Américas, el Mediterráneo Oriental, Asia Sudoriental y el Pacífico Occidental, siendo las últimas dos regiones las más afectadas. A medida que la enfermedad se propaga a nuevas zonas, no sólo aumenta el número de casos, sino que se están produciendo brotes explosivos. En 2007, en Venezuela se notificaron más de 80.000 casos, entre ellos más de 6.000 de DH.

La propagación del dengue se atribuye a la expansión de la distribución geográfica de los cuatro virus del dengue y sus mosquitos vectores, los cuales son predominantemente urbanos. Debido a este motivo, el aumento rápido de las poblaciones urbanas de mosquitos está incrementando el número de personas en contacto con este vector, especialmente en zonas favorables a la reproducción de los mosquitos, como en las existe almacenamiento doméstico de agua y no se disponen de servicios adecuados de eliminación de residuos sólidos (OMS, 2009).

\section{Situación en América}

El dengue en las Américas durante los últimos años, ha tenido una tendencia ascendente con pick epidémicos que se repiten cada 3 a 5 años casi de manera estable. El país con mayores tasas de incidencia es Brasil, que ha llegado, en ocasiones, a acumular casi el $80 \%$ de todo el dengue de las Américas. Le siguen la región Andina y Centroamérica. Actualmente, Brasil, Paraguay y Bolivia registran los más altos índices de casos de dengue, situación que ya fue alertada por la Organización Panamericana de la Salud (OPS) a fines de 2011. Figura 2.

Figura 2. Aumento de la incidencia de dengue en América del Sur (1980-2011).Fuente OPS.

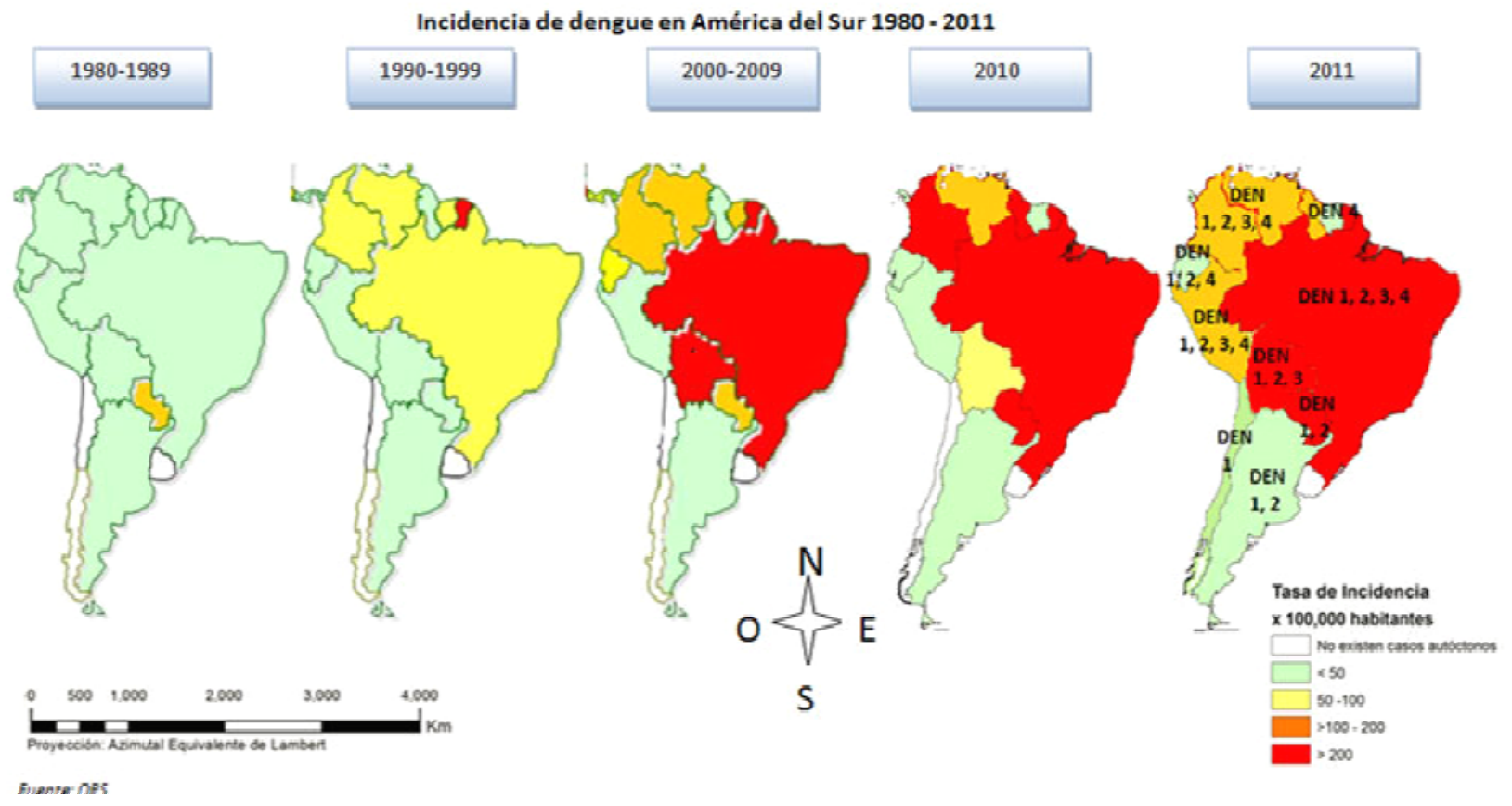


Entre 1948 y 1972 el A. aegypti, mosquito vector del dengue y de la fiebre amarilla, fue erradicado en 21 países de la Región. En 1997, prácticamente todos los países de la Región de las Américas se encontraban reinfectados, incluyendo el sur de los Estados Unidos, y han ocurrido numerosas epidemias de dengue y de dengue hemorrágico en la Región, lo que se ha convertido progresivamente en un problema de salud pública (OPS y OMS, 1997). La re-emergencia del dengue en las Américas comenzó en la década de los años 60 durante la cual se produjeron importantes epidemias en Venezuela y varias islas del Caribe, incluyendo Jamaica y Puerto Rico (OMS y OPS, 1997). En la segunda mitad de la década de los años 70 se reintrodujo el dengue 1 en las Américas ocasionando una pandemia que afectó países de Centroamérica (El Salvador, Guatemala y Honduras), México, Estados Unidos, los países del norte de América del Sur (Colombia, Guayana Francesa, Guyana, Surinam y Venezuela), así como prácticamente todas las islas del Caribe. En la década de los años 80 , vuelven a registrarse varias epidemias importantes en países endémicos y ocurre la expansión del dengue 1 a América del Sur. Así se observaron brotes en cinco países: Bolivia, Brasil, Ecuador, Paraguay y Perú, los cuales habían permanecido libres de dengue por varias décadas o que jamás habían notificado la enfermedad (OMS y OPS, 1997).

Los dos últimos países de América infestados por $A$. aegypti libres del dengue (Costa Rica y Panamá) informaron transmisión autóctona del dengue en 1993. En el año siguiente el serotipo 1, fue detectado casi simultáneamente en Panamá y Nicaragua, siendo en
Nicaragua donde se originó una epidemia de dengue y de dengue hemorrágico. En el año 1995 el dengue tipo 3 se diseminó a otros países de Centroamérica (excepto Belice) y a México, causando brotes importantes. Debido a que el dengue 3 no circulaba en las Américas desde 1978, se estimó que 200 millones de personas susceptibles residen en áreas infestadas por el $A$. aegypti, por lo que existe el riesgo de diseminación del serotipo y la ocurrencia de epidemias importantes. En 1995, existieron epidemias de dengue en Centroamérica, el Caribe y América del Sur (particularmente Brasil) con un total de 300.000 casos notificados por 41 países, lo que representa la mayor incidencia de dengue desde 1981. En 1996 fueron informados 250.707 casos, de los cuales alrededor del 80\% ocurrieron en Brasil (OMS y OPS, 1997).

Respecto del Dengue Hemorrágico (DH) la primera epidemia en las Américas fue causada por el dengue tipo 2 en Cuba en el año 1981. Durante la misma se notificaron 344.203 casos de dengue incluidos 10.312 casos graves de dengue hemorrágicos y 158 defunciones. La segunda epidemia se registró en Venezuela en 1989-1990, durante la cual se notificaron 5.990 casos y 70 defunciones. Los virus en circulación fueron los serotipos 1, 2 y 4, aunque en los casos fatales solo se detectó el dengue tipo 2. Alrededor de dos tercios de los casos y de las defunciones de dengue hemorrágicos notificados por Cuba y Venezuela fueron de niños menores de 14 años. Posteriormente, en todos los demás años se han notificado casos de dengue hemorrágico en las Américas. En la tabla 1 se señala el reporte de casos de dengue para en las subregiones de las Américas

\begin{tabular}{cccc}
\hline Subregión & Dengue clásico & Dengue hemorrágico & Muertes \\
\hline Andina & 72.576 & 4.485 & 24 \\
\hline América Central & 43.644 & 2.612 & 7 \\
\hline Sur América & 110.463 & 77 & 3 \\
\hline Caribe & 6.749 & 178 & 16 \\
\hline
\end{tabular}

Tabla 1. Casos de dengue reportados en las Américas:

\section{Control Integrado del Vector}

A lo largo de la historia, el único método de controlar o prevenir la transmisión de los virus del dengue consiste en la lucha contra los vectores (OMS, 2009). Hasta hace pocos años, los modelos para el control del dengue no eran suficientemente integrados $y$ participativos y no abordaban el problema en toda su 
magnitud y dimensiones. Su principal deficiencia era que no traspasaban las fronteras del sector salud, por lo que no tenían alcance intersectorial. La falta de un tratamiento específico y de una vacuna efectiva contra el dengue obliga a diseñar nuevas estrategias que rompan los esquemas verticales tradicionales y que impulsen cambios conductuales y el empoderamiento de los ciudadanos según las particularidades de cada país. (Brathwaite-Dick y San Martin, 2007)

Es debido a esta situación, que en 1999, la OMS presentó una estrategia mundial para la prevención y el control del dengue, y en el 2001, del dengue hemorrágico. Así mismo la OPS formuló las directrices regionales para la prevención y el control del dengue, contenidas en la Resolución CD43.R4 de su Consejo Directivo. Estos lineamientos, perseguían promover una nueva generación de programas para reforzar los mecanismos de prevención y control del dengue; y los programas nacionales mediante la participación comunitaria, la educación sanitaria y la coordinación de acciones extrasectoriales, ya fuera con organizaciones gubernamentales o no gubernamentales. En el año 2003, durante el $44 .^{\circ}$ Consejo Directivo de la OPS/OMS, se aprobó la Resolución CD44.R9, cuyo objetivo es promover un cambio en el enfoque de los programas nacionales. Esa resolución contenía nuevas recomendaciones sobre las formas y los métodos que se debían aplicar a la cooperación técnica de la Organización, introducía el modelo de la EGI-dengue y creaba un grupo técnico de trabajo sobre el dengue en la Región (GT-dengue internacional).

La EGI-dengue es un modelo de gestión que tiene como objetivo fortalecer los programas nacionales con vistas a reducir la morbilidad, la mortalidad y la carga social y económica generada por los brotes y las epidemias de dengue. Para alcanzar sus objetivos, esta estrategia busca modificar la conducta de las personas y de la comunidad de manera que disminuyan los factores de riesgo de transmisión con medidas coordinadas, tanto dentro como fuera del sector salud, es decir, con una mirada interdisciplinaria bajo el concepto “Una Salud”. Además, llama a elaborar y ejecutar planes nacionales y subregionales integrados que permitan trazar una estrategia nacional sostenible, diseñada por las autoridades y los especialistas de cada país con la cooperación técnica del GT-dengue internacional. Estas estrategias nacionales y regionales deben tener un enfoque interprogramático, integrado e intersectorial, basado en una nueva práctica, que permita evaluar y dar continuidad a las acciones con recursos nacionales.

La EGI-dengue agrupa áreas de acción y componentes claves que tienen la mayor responsabilidad en la planificación y ejecución de las actividades de prevención y control del dengue. Entre esas áreas se encuentran: la comunicación social, la vigilancia epidemiológica, el servicio de laboratorio, la atención al paciente, los servicios entomológicos y la gestión ambiental.

Hasta el año 2011, 18 países de la región de las Américas y las cuatro sub regiones han diseñado e implementado sus estrategias y en estos momentos se trabaja por completar los países del Caribe. En esos 18 países se concentra cerca del 95\% de la morbilidad por dengue que reporta toda la Región (OPS, 2011).

En los países en los que se ha implementado la EGIDengue se ha producido un intercambio constante entre las áreas técnicas y los responsables de tomar decisiones en los ministerios y los municipios. Esto ha permitido generalizar y difundir las experiencias $\mathrm{y}$ lecciones aprendidas en cada uno de los diferentes componentes (OPS, 2011).

\section{Situación en Chile}

Si bien, en Chile continental no se ha documentado la existencia del mosquito del dengue de forma endémica, si se ha hecho en Chile Insular, más específicamente en Isla de Pascua, donde en el año 1998, la población residente había notado la presencia de un mosquito diferente a los conocidos, aumentando de este modo las consultas médicas por patologías de la piel (Olea y Ballester, 2001). $\quad \mathrm{Al}$ año siguiente, el Departamento de Epidemiología del Ministerio de Salud decidió incluir al dengue dentro del listado de Enfermedades Transmisibles de Notificación Obligatoria. Se alertó a los Servicios de Salud para que vigilaran la aparición de casos, definieran modalidades de vigilancia y criterios de laboratorio, contando con la capacidad profesional del ISP (Olea y Ballester, 2001).

El 2000, se toma conocimiento de la presencia del vector Aedes aegypti en Isla de Pascua. Así, ante la 
presencia de un nuevo mosquito en la Isla, se tomaron las siguientes medidas (Olea y Ballester, 2001):

\section{Plan de Erradicación del Aedes Aegypti de Isla de Pascua.}

- Vigilancia entomológica para la identificación del vector y su ubicación: Implementación de un laboratorio entomológico básico en el DPA (Departamento de Programas sobre el Ambiente) del Hospital Hanga Roa, para identificar las muestras de larvas y ejemplares adultos capturados en la isla, no solo de aedes, sino también de anofelinos y triatóminos.

- Control biológico a través del uso de Bacillus thuringiensis, en estanques de aguas, pozos y piscinas, con el fin de evitar el crecimiento larvario.

- Control químico mediante fumigación de interior y exterior de las casas con piretroides, durante el verano. Sumado a lo anterior, se dio orden de fumigar todos los aviones provenientes de zonas endémicas.

- Establecimiento de un sistema de vigilancia de febriles. El hospital debe identificar los casos sospechosos de acuerdo a la definición de caso, tomar la muestra de sangre y enviarla al ISP para su análisis. Una vez realizado esto, el ISP debe comunicar el resultado al laboratorio local, Servicio de Salud y Nivel Central. El epidemiólogo del Servicio de Salud será el que clasifique el caso y lo notifique al MINSAL.

- Capacitación de clínicos en reconocimiento del Dengue

- Fortalecer la capacidad diagnóstica del laboratorio

- Realizar campaña educativa para la prevención. Se intenta priorizar la educación de la comunidad a través de dos estrategias: 1campaña publicitaria y 2- modalidad "casa a casa” con monitores Rapa Nui capacitados en medidas preventivas contra Aedes aegypti.

- Presentación histórica de casos en Isla de Pascua

En el año 2002 se infecto aproximadamente el 80\% de los habitantes de Isla de Pascua, con el serotipo DEN-
1. Cuatro años más tarde, en el 2006, se registraron 3 casos. En el 2007 la cifra aumentó a 27, para permanecer estable más tarde en el 2008 y 2009 con 25 casos cada año. El bajo número de individuos susceptibles que dejó el brote del año 2002 explicaría la baja en el número de casos registrados. Sumado a lo anterior, todos los casos posteriores correspondieron igualmente al serotipo DEN-1, salvo 3 casos del año 2009 que pertenecieron al serotipo DEN-4 (MINSAL, 2012a). En Chile continental, se ha dispuesto una serie de medidas tendientes a vigilar la posible introducción del mosquito, aun cuando, no hay reportes de casos autóctonos de dengue porque no circula el vector que transmite la enfermedad. La razón de realizar vigilancia, es debido a que en los países vecinos circula ampliamente el Aedes aegypti y la enfermedad es endémica, sumado a la presencia del vector en la Isla de Pascua.

\section{Casos importados}

Hasta la fecha, se han presentado 2 casos importados de dengue, ambos notificados en la región Metropolitana, con antecedentes de viajes recientes a Colombia y Brasil. En el año 2011, se confirmaron 10 casos de dengue importado, $80 \%$ procedentes de Centro y Sudamérica (MINSAL, 2012b).

\section{Conclusión}

El dengue es una enfermedad vectorial clasificada como desatendida que representa un flagelo mundial, ya que afecta a millones de personas especialmente los más pobres del mundo. Por otro lado, debido al cambio climático y la globalización esta enfermedad está emergiendo y re-emergiendo extendiéndose a muchas regiones no endémicas, por lo que debe ser una preocupación mundial, es así que se deben mejorar los esfuerzos de coordinación públicos y privados para abordar esta enfermedad desde una perspectiva multidisciplinaria incluyendo los factores clínicos, ambientales y sociales. 


\section{Referencia}

1. Brathwaite-Dick, O; San Martín, J. 2007. La Estrategia De Control Integrada Para La Prevención Y Control Del Dengue En Las Américas. Revista Panamericana De Salud Pública. [En Línea $]<$ Http://Www.Scielosp.Org/Scielo.Php?Pid=S1 $020-$ 49892007000100011\&Script=Sci_Arttext> [Consulta: 23-07-2011]

2. Guzmán, M.; Kourí, J. 2001. Flavivirus. In: Llop Hernández Et.Al. Microbiología Y Parasitología Médicas. Editorial Ciencias Médicas. La Habana, Cuba. Pp. 309-320.

3. Mackey, T; Liang, B. 2012. Threats From Emerging And Re-Emerging Neglected Tropical Diseases (Ntds). Infection Ecology And Epidemiology. Doi: 10.3402.

4. Marcano-Pasquier, R. 2010. Mosca Con El Dengue, Que Vienen Las Lluvias. Medicina Preventiva Santa Fe [En Línea] < Http://Www.Medicinapreventiva.Com.Ve/Art iculos/Dengue.Htm> [Consulta: 25-07-11]

5. Minsal. Ministerio De Salud. 2011. Dengue En Isla De Pascua. Situación Epidemiológica Al 29 De Julio De 2011. [En Línea] $<$ Http://Epi.Minsal.Cl/Epi/Html/Bolets/Report es/Dengue/Informedengue.Pdf $>$ [Consulta: 30-07-2012]

6. Minsal. Ministerio De Salud. 2012a. Dengue Antecedentes Generales. [En Línea] $<$ Http://Epi.Minsal.Cl/Epi/Html/Enfer/Prevde ngueweb.Pdf $>$ [Consulta: 28-06-2012]

7. Minsal. Ministerio De Salud. 2012b. Informe De Dengue (Cie 10: A90 - A91). [En Línea] $<$ Http://Epi.Minsal.Cl/Epi/Html/Bolets/Report es/Dengue/Informedengue.Pdf $>$ [Consulta: 28-06-2012]

8. Salvatella, R. 1996. Aedes Aegypti, Aedes Albopictus (Diptera, Culicidae) Y Su Papel Como Vectores En Las Américas. La Situación De Uruguay. [En Línea] $<$ Http://Www.Bvsde.Paho.Org/Bvsasv/Fulltex t/Aede.Pdf > [Consulta: 19-07-11]

9. Oms. Organización Mundial De La Salud. 2009. Centro De Prensa. Dengue Y Dengue
Hemorrágico. [En Línea] < Http://Www.Who.Int/Mediacentre/Factsheets/ Fs117/Es/Index.Html> [Consulta: 30-072011]

10. Oms, Ops. 1997. Informe Sobre El Control Del Aedes Aegypti. Washington. D.C., E.E.U.U. 47 Pp.

11. Ops. Organización Panamericana De Salud. 2011. Alerta Epidemiológica: Actualización Sobre La Situación Del Dengue En Las Américas. [En Línea] < Http://New.Paho.Org/Hq/Dmdocuments/2011 /Alertas_Epi_18_Marzo_2011_Actualizacion _Dengue1.Pdf $>$ [Consulta: 30-07-2011].

12. Ops. Organización Panamericana De Salud. 2012. Notas Descriptivas: Dengue. [En Línea] $<$

Http://New.Paho.Org/Hq/Dmdocuments/2011 /Alertas_Epi_18_Marzo_2011_Actualizacion _Dengue1.Pdf> [Consulta: 30-06-2012]

13. Olea, A; Ballester, J. 2001. Aedes Aegypti En Isla De Pascua. Ministerio De Salud. Boletín De Vigilancia En Salud Pública De Chile El Vigía, №13, Pp 2-5. 